\title{
JURIMETRIA. A ESTATÍSTICA E A IMPORTÂNCIA DA PREVISÃO DE COMPORTAMENTOS NO DIREITO ${ }^{1}$
}

\author{
JURIMETRICS. THE STATISTICS AND THE IMPORTANCE OF PREDICTING \\ BEHAVIOR IN THE LAW
}

\section{JURIMETRÍA. LA ESTADÍSTICA Y LA IMPORTANCIA DE LA PREVISIÓN DE COMPORTAMIENTOS EN EL DERECHO}

\section{Karina Reis}

\section{Moacyr $^{2}$}

RECEBIBO 29/01/2019

APROVADO 30/01/2019

PUBLICADO 04/01/2019

Editor Responsável: Carla Caldas

Método de Avaliação: Double Blind Review

E-ISSN: 2316-8080

DOI: 10.16928

\section{RESUMO}

O Direito brasileiro passa por forte crise de identidade. A tradicional adoção de metodologias isolacionistas, que distanciam a realidade do estudo teórico, são encaradas como ineficazes pelos jurisdicionados, tendo em vista que o contexto de crescimento tecnológico exponencial exige estudos jurídicos que acompanhem o ritmo acelerado da sociedade. Neste cenário, a análise multidisciplinar do Direito favoreceu o desenvolvimento de um viés quantitativo que passou a ser denominado de Jurimetria. A coleta de dados procedida do estudo estatístico seria capaz de trazer conclusões numéricas traduzidas em percentuais. Este intercâmbio de informações suscitou em alguns cientistas questionamentos ousados lastreados na possibilidade de se prever comportamentos jurídicos. Para discutir o termo "previsão", o presente artigo introduz a teoria filosófica denominada probabilidade pragmática, a qual tem sido utilizada no desenvolvimento da inteligência artificial, proporcionada pela lógica indutiva paraconsistente. O resultado dos estudos probabilísticos no Direito, através da utilização de software avançado, reflete diretamente na criação do instituto da advocacia preventiva,

\footnotetext{
${ }^{1}$ Artigo elaborado em maio de 2017.

${ }^{2}$ Advogada, graduada pela Faculdade de Direito da Universidade Federal da Bahia, pós-graduanda em LL.M Direito Corporativo no IBMEC - Instituto Brasileiro de Mercado de Capitais, contato: karinareis@reisdesa.adv.br, ORCID ID: https://orcid.org/0000-0003-4713-4471.
}

PIDCC, Aracaju/Se, Ano VIII, Volume 13 no 01, p.110 a 131 Fev/2019 | www.pidcc.com.br 
caracterizada por traçar estratégias jurídicas criativas que analisam o cenário de forma antecipada e precisa com o objetivo de conduzir as tomadas de decisão e evitar situações potencialmente conflituosas ao cliente.

PALAVRAS-CHAVE: Jurimetria. Multidisciplinaridade. Previsão de Comportamentos. Banco de Dados. Probabilidade Pragmática. Lógica Paraconsistente. Advocacia Preventiva.

\begin{abstract}
Brazilian law goes through a strong identity crisis. The traditional prevalescence for isolationist methodologies, which used to distance reality from theoretical study, is seen as ineffective for right holders, given that the context of exponential technological growth requires legal studies that accompany the accelerated pace of society. In this scenario, the multidisciplinary analysis of Law favored the development of a quantitative bias that became known as Jurimetrics. The collection of data from the statistical study would be able to bring numerical conclusions translated into percentages. This exchange of information has instilled in some scientists bold questions, based on the possibility of predicting legal behavior. To discuss the term "prediction", the present article introduces the philosophical theory called pragmatic probability, which has been used in the development of artificial intelligence, provided by the paraconsistent inductive logic. The result of a probabilistic studies in Law, using an advanced software, directly reflects the creation of the institute named preventive advocacy, characterized by creative legal strategies that analyze the scenario in an anticipated and precise way to conduct decision-making and potentially conflicting situations.
\end{abstract}

KEYWORDS: Jurimetrics. Multidisciplinarity. Predict Behavior. Big Data. Pragmatic Probability. Paraconsistent Logic. Preventive Advocacy.

\title{
RESUMEN
}

El Derecho brasileño está a pasar por una fuerte crisis de identidad. La tradicional adopción de metodologías aislacionistas, que alejan la realidad del estudio teórico, son consideradas como ineficaces por los titulares del derecho, cuando se tiene en cuenta el contexto de crecimiento tecnológico en magnitud exponencial y requiere estudios jurídicos que acompañen el ritmo acelerado de la sociedad. En este escenario, el análisis multidisciplinario del Derecho ha favorecido el desarrollo de una perspectiva quantitativa la cual fué denominada de Jurimetría. Los datos recolectados procedidos del estudio estadístico sería capaz de exhibir PIDCC, Aracaju/Se, Ano VIII, Volume 13 no 01, p.110 a 131 Fev/2019 | www.pidcc.com.br 
conclusiones numéricas convertidas en porcentajes. Este intercambio de información ha suscitado en algunos científicos cuestionamientos audaces basados en la posibilidad de pronosticar comportamientos jurídicos. Para discutir el término "previsión", el presente artículo introduce la teoría filosófica denominada probabilidad pragmática, la cual ha sido utilizada en el desarrollo de la inteligencia artificial, proporcionada por la lógica inductiva paraconsistente. El resultado de los estudios probabilísticos en el Derecho, a través del uso de software avanzado, refleja directamente en la creación del instituto de la abogacía preventiva, distinguida por proyectar estrategias jurídicas creativas que analizan el escenario de forma anticipada y estricta con el objetivo de direccionar las tomas de decisiones y precaver situaciones potencialmente conflictivas al cliente.

PALABRAS CLAVE: Jurimetría. enfoque multidisciplinario. Previsión de Comportamientos. Banco de datos. Probabilidad Pragmática. Lógica Paraconsistente. Abogacía Preventiva.

\section{INTRODUÇÃO}

O estudo do Direito no Brasil, influenciado pelas tradições romano germânicas, desenvolveu-se com um viés que sobrepõe a teoria à prática. $\mathrm{O}$ caráter isolacionista limitou sua análise a axiomas lógico-formais próprios, dificultando uma contextualização multidisciplinar dos fatos jurídicos.

Se for considerado que a finalidade do Direito é justamente a manutenção do equilíbrio coletivo, como é possível alcançá-la sem um diálogo com seus receptores ou jurisdicionados? Os cientistas afirmam que o Direito passa por forte crise, tendo em vista a utilização de uma metodologia que distancia a realidade da teoria. Ao fundamentar-se unicamente em visões determinísticas, dogmáticas e argumentos de autoridade, ignora relevantes questões sociais da academia.

Em 1949, o advogado norte-americano Lee Loevinger observou um possível distanciamento entre a crescente quantidade de normas criadas em seu país e os fatos jurídicos. Esta situação motivou a realização de experimentos com viés multidisciplinar utilizando critérios qualitativos e quantitativos. A metodologia que encara o mundo jurídico a partir de princípios da Matemática e Estatística foi denominada pelo autor de Jurimetria. 
A Jurimetria interpreta o Direito através de porcentagens obtidas com o estudo e coleta de informações sobre casos pretéritos, escolhidos de forma aleatória. O objetivo é oferecer respaldo e maior precisão aos argumentos jurídicos. Entretanto, a consequência mais polêmica do estudo jurimétrico consiste na possibilidade de se prever comportamentos jurídicos.

O presente artigo apresenta o conceito de Jurimetria como metodologia multidisciplinar capaz de aproximar o Direito da realidade. Após a explicação sobre o funcionamento da pesquisa estatística, discute com profundidade se é possível prever comportamentos sem mecanizar as relações humanas, com fulcro na Teoria das Probabilidades. $\mathrm{O}$ artigo é finalizado com exemplos da utilização da Jurimetria nas atividades dos advogados, expondo resultados de projetos que discutem a sua eficácia.

A metodologia utilizada para o alcance destes objetivos foi a pesquisa exploratória e bibliográfica, com abordagem histórica. Por fim, a pesquisa teórica destacou-se na abordagem sobre existência de casos semelhantes e sua relação com a Teoria das Probabilidades.

\section{A JURIMETRIA}

\section{1 HISTÓRICO E CONCEITO}

O termo Jurimetria foi cunhado pelo advogado norte-americano Lee Loevinger, em seu artigo Jurimetrics: the methodology of legal inquiry (LOEVINGER, 1963), como uma atividade envolvendo investigação científica de problemas legais, ou seja, utilização de experimentos no Direito, assim como ocorre nas ciências naturais, diretamente associada à análise quantitativa e estatística.

Loevinger analisou pesquisas experimentais realizadas em universidades renomadas do seu país, com destaque aos projetos Health Law Center, em University of Pittsburgh, o Semantic Coded Abstract, na Western Reserve University, o Point Of Law, em Oklahoma State University, finalizando com o Jury Project, em University of Chicago Law School. Através da coleta e armazenamento de dados jurídicos, concluiu que um dos principais benefícios da recuperação de dados legais é encontrar o precedente aplicável, análogo ou relevante a um caso atual. Destarte, o precedente aplicável deveria ser estudado com critérios que observassem a unificação da abordagem teórico quantitativa e empírico quantitativa dos problemas jurídicos, denominada Jurimetria (LOEVINGER, 1963).

O Direito foi relacionado a métodos quantitativos pela primeira vez no início do século XVIII pelo matemático Bernoulli (1709 apud ZABALA; SILVEIRA, 2014) que escreveu sua PIDCC, Aracaju/Se, Ano VIII, Volume 13 no 01, p.110 a 131 Fev/2019 | www.pidcc.com.br 
tese de doutorado titulada De usu artis conjectandi in jure, abordando a probabilidade de sobrevivência de pessoas, precificação de seguros e loterias. O próprio Oliver Holmes (1897), "pai da common law", declarou em seu livro The path of law que o homem do futuro é o homem da Estatística e mestre em Economia.

Apesar dos métodos quantitativos já terem sido aplicados ao Direito ao longo da História, foi o termo cunhado por Loevinger que inspirou a criação de um periódico trimestral, denominado Jurimetrics Jounal, produzido pelo American Bar Association (1858), com o objetivo de abordar diversas questões sobre Jurimetria nos Estados Unidos. O periódico atualmente é on line e produz artigos sobre o tema, haja vista a intensidade da utilização da estatística e armazenamento de dados no país.

Michael Heise ${ }^{3}$, considerado por muitos, uma das maiores autoridades mundiais no estudo empírico e estatístico no âmbito jurídico, corrobora com a tese de Loevinger e acrescenta que o Direito deveria transcender os estudos com uma abordagem quantitativa para compreender também um aspecto qualitativo, no qual a Estatística não seria apenas uma ferramenta adequada de análise. A despeito disto, haveria a junção de métodos e técnicas como o estudo de caso, a investigação participativa, a observação participante, ou seja, uma análise com viés verdadeiramente multidisciplinar (HEISE, 1999).

No Brasil, Marcelo Nunes, o presidente da Associação Brasileira de Jurimetria, criada publicou juntamente com Fabio Ulhoa Coelho, artigo on line titulado Pesquisas a serviço da advocacia, no qual expôs o resultado de um trabalho sobre intervenção judicial em administração de empresas, constatando os fundamentos mais aceitos pelos juízes para negar ou aceitar a intervenção (NUNES; COELHO, 2010).

Classicamente os objetos de estudo do Direito são as análises das normas, suas possíveis interpretações e os conceitos jurídicos através de uma perspectiva teórica. Embora tal visão seja fundamental, seu estudo não deveria restringir-se à análise dos possíveis significados das leis. Criada em 2009, a Associação Brasileira de Jurimetria (ABJ) ${ }^{4}$ destaca a importância de ir além,

\footnotetext{
${ }^{3}$ Desde 2005, Michael Heise é editor do Journal of Empirical Legal Studies, uma revista interdisciplinar que publica artigos empiricamente orientados e de interesse de uma área diversificada de estudiosos do Direito. Tanto a análise de dados experimentais e não experimentais são incluídas no estudo, assim como estudos relacionados com o direito de todo o mundo. O jornal pode ser consultado através do endereço eletrônico: http://onlinelibrary.wiley.com/journal/10.1111/(ISSN)1740-1461.

4 “A Associação Brasileira de Jurimetria busca contribuir para o aperfeiçoamento da sociedade brasileira através do levantamento de subsídios empíricos e quantitativos para elaboração de políticas públicas, sempre tendo em vista três missões principais:1. Disciplinar a Jurimetria como um ramo do conhecimento jurídico, definindo suas premissas, seus fundamentos e seus conceitos. 2. Reunir e incentivar pesquisadores com preocupação em investigar os processos de decisão do direito. 3. Colaborar com entidades públicas e privadas no esforço estratégico de aperfeiçoar os mecanismos de prestação jurisdicional e administração da justiça". Associação Brasileira de Jurimetria. Acesso em 23 fev. 2016: http://abjur.org.br/quem-somos-missao.php.
} 
estudando também as características concretas dos processos jurídicos de decisão. É importante entender como os fatos, atos e negócios que concretizam o Direito se dão no cotidiano da vida em sociedade.

A partir da criação da ABJ, o tema passa a ser debatido no país com maior intensidade. Mas como o Direito brasileiro possui a tradição de utilizar essencialmente os métodos formais e abstratos, constituindo verdadeiro argumento de autoridade, consolidou-se uma mentalidade de repúdio e insegurança pela realização de métodos experimentais. A consequência disto foi a dificuldade na formação de um banco de dados eficiente e confiável e, portanto, sua expansão tem sido bastante lenta.

O advogado Fabiano Feijó Silveira e o estatístico Filipe Zabala (2014, p. 89-90) também resolveram investir na pesquisa jurimétrica. $\mathrm{O}$ resultado prático foi revelado com a publicação do artigo Jurimetria: Estatística aplicada ao Direito que objetivou introduzir a Jurimetria no meio jurídico brasileiro no intuito de solucionar e regulamentar os conflitos de forma fundamentada, considerando que a Estatística baseia-se em um estudo de variáveis reais, as quais são ordenadas e calculadas com o fim de verificar qual o caminho que mais se aproxima da realidade.

De acordo com o artigo, a Estatística utilizada no Direito teria o objetivo inicial de generalizar resultados para introduzir ou nortear os juristas em relação à forma que determinada situação vem ocorrendo na prática. A união de variáveis estatísticas é uma operação realizada com o fim de obter resultados mais exatos e menos subjetivos. $\mathrm{O}$ alcance de resultados objetivos no mundo jurídico oferece previsibilidade de comportamento aos que atuam em seu universo (ZABALA; SILVEIRA, 2014, p. 89-90). A generalização para a Jurimetria seria apenas um meio de estudo, um pontapé inicial para análise das especificidades de cada caso, pois a união de variáveis calculadas objetivamente serviria como valioso meio de prova para fundamentar a veracidade de tese de advogados, as decisões dos magistrados e a eficácia na elaboração das leis.

Compreende-se, portanto, que a Jurimetria não se fundamenta exclusivamente no estudo do Direito e da Estatística. Sua constituição perpassa por tópicos como a Ciência da Matemática, Economia, Computação, Linguística e Comportamento Humano, caracterizandose por uma aproximação da disciplina jurídica aos métodos quantitativos, sem desconsiderar os métodos qualitativos, na construção de em uma análise interdisciplinar.

\subsection{A EPISTEMOLOGIA DA “CIÊNCIA DO DIREITO" E A} INTERDISCIPLINARIDADE. 
As tentativas de superação do formalismo ainda são muito recentes no Direito brasileiro, de tradição romano-germânica, teve suas bases fincadas no Direito francês, caracterizado por normas escritas, gerais e abstratas. Além disto, a "teoria pura do Direito", sustentada pelo positivismo jurídico kelseniano, influenciou fortemente o país a partir da premissa da constituição de um conteúdo ideal e normativo, que faz parte do mundo do "dever ser" e possui validade por si só, independentemente de postulados éticos ou relações com a Sociologia, Política e Economia (KELSEN, 1998, p.50).

A despeito de Hans Kelsen ter sido professor nos Estados Unidos, "a teoria pura do Direito" não teve força neste país, haja vista o fato de que o sistema jurídico norte-americano era encarado pela análise pragmática de Oliver W. Holmes (1897, p.12), fundador do realismo jurídico e autor, no final do século XIX, da impactante afirmação de que os juristas aprenderiam a considerar e a pesar os fins legislativos, os meios de alcançá-los e o custo envolvido. Influenciando toda uma geração de juristas do início do século XX, o realismo propunha uma nova ontologia, pautada na abertura de perspectivas científicas de distintas disciplinas (Sociologia, Psicologia, Economia, Estatística). Resta evidente, portanto, que sua tendência sintetizava uma visão epistemológica diametralmente oposta ao idealismo kelseniano, tão influente nos países romano-germânicos (ZANATTA, 2011).

Ao analisar a receptividade do realismo jurídico no Brasil, constata-se um crescimento em percentual ínfimo se comparado ao grau de rejeição. Esta conclusão lastreia-se em uma má interpretação das suas finalidades que acabam igualando os métodos quantitativos à discussão sobre física e metafísica, distanciando do debate jurídico a possibilidade do seu uso. Entretanto, a rejeição feita de forma superficial, sem estudar de fato o movimento que reúne o Direito a matérias quantitativas mantém o mundo jurídico no Brasil extremamente teórico e alheio à sociedade.

A lógica, tanto no Direito como nas matérias exatas, busca tratar de estruturas de pensamento. Ao expurgar tudo que é do mundo natural ou social, é útil ao sistema por auxiliar a sintaxe dos comandos a serem obedecidos pelo ordenamento formal (SILVA, 2012). Porém, o mundo jurídico precisa validar o seu discurso científico, o que não ocorre quando a realidade é analisada em apartado com a teoria. Esta forma de estudo substitui a ciência por visões determinísticas, dogmáticas e argumentos de autoridade, afastando também relevantes questões sociais da academia (CASTRO, 2015, p.66). 
Destarte, o grande problema do estudo jurídico brasileiro é a sua restrição a estruturas lógicas de pensamentos que validam a busca de um discurso e argumentação mais coerente. $\mathrm{O}$ Direito, projetado para ser um sistema social que buscaria organizar as relações entre os jurisdicionados, criando um marco civilizatório em permanente transformação, foi reduzido a um instrumento alheio à sociedade, utilizando-se de conceitos ideais de justiça, ineficazes na prática (PINTO; MENEZES, 2015?).

Os impactos sociais da aplicação da lei ao caso concreto, especialmente daquela resultante de um processo judicial, constituem elementos de pouco estudo no mundo jurídico. No máximo, um único caso isolado é utilizado como referencial, resultando em uma carência de análise sistemática que possibilite conclusões precisas sobre sua aplicação para as partes e para todos os setores da sociedade.

As distorções causadas pelo estudo e aplicação do Direito de forma isolacionista refletem diretamente a atuação limitada da maioria dos escritórios de advocacia brasileiros. Estes advogados ainda não conseguem imaginar o quanto pode ser útil um trabalho preventivo oferecido aos seus clientes, evitando conflito ou deixando-os preparados para fatos futuros, através da análise das previsibilidades, proporcionada pela Jurimetria.

Destarte, como a epistemologia trata de identidade cientifica ou crise de identidade, além de aferir questões de cunho teleológico, muitos juristas defendem que o Direito brasileiro vive seu momento de crise (PINTO; MENEZES, 2015?, p.63) Questiona-se a possibilidade de desenvolver o caráter científico no Direito, sem a perda da sua identidade, chegando-se à conclusão que, para verificar a aplicabilidade e eficácia das teorias, estas devem ser testadas, e são os métodos quantitativos que apuram os resultados dos testes, conjugando suas interpretações às teorias matemáticas, estatísticas, econômicas e até psicológicas (p.57).

Em busca de soluções para as limitações causadas pelo formalismo kelseniano, a interdisciplinaridade é apontada como caminho possível para novas formas de pensar o Direito atual. O método científico da interdisciplinaridade consiste na comunicação de diferentes disciplinas, no confronto e discussão de suas perspectivas, estabelecendo entre si uma interação (ZANATTA, 2011). Os resultados destes trabalhos são elaborações de teses jurídicas que conquistam seguidores pela utilidade e amparo social, justificadas por estudos de campo, interpretados e posteriormente exibidos através de números.

\subsection{O ESTUDO DA ESTATÍSTICA NO DIREITO}


A ideia basilar da Jurimetria é estudar o Direito de forma multidisciplinar, utilizando teses que têm como essência métodos quantitativos, como a Estatística, Matemática e Economia com o escopo de aproximar os resultados da pesquisa à realidade da população em análise. Muitos juristas ficarão surpresos com a possibilidade de estudos essencialmente numéricos relacionarem-se de forma efetiva com os fenômenos sociais, que geralmente constituem objeto das ciências humanas. Então, o presente tópico irá expor de forma bastante sintética o objetivo da Estatística, bem como os conceitos basilares da disciplina.

Inicialmente, o estatístico irá buscar seu material de pesquisa referente à amostra ou população em análise, através de uma técnica que computa, numera e mede os fatos relacionados. Os dados obtidos serão coordenados e classificados com o objetivo de determinar suas causas, consequências e tendências. A estatística descritiva compreende a coleta, análise e apresentação através da organização, representação gráfica e descrição dos dados coletados, facilitando sua compreensão. Posteriormente, utiliza-se a estatística inferencial com o objeto de interpretar as características de uma população a partir de dados observados em uma amostra de indivíduos (BISQUERRA; SARRIERA, 2007). Uma boa descrição dos dados pode levantar hipóteses bastante interessantes do fenômeno estudado.

Saliente-se que a população na Estatística é entendida como um conjunto de elementos com características comuns. Destarte, para fazer a inferência é necessária a obtenção aleatória de uma amostra representativa dos dados populacionais. Dos membros de uma população podemos levantar características, opiniões ou fatos que variam de elemento para elemento. Estas são as variáveis, as quais podem ser classificadas basicamente como qualitativas e quantitativas. As primeiras referem-se a um atributo do indivíduo pesquisado, como o sexo ou estado civil, enquanto as quantitativas são passíveis de comparação através de uma mensuração (SERRA, 2013).

Ao relacionar o Direito com a Estatística e Matemática, o pesquisador deverá escolher a população ou amostra a ser explorada (Leis Municipais, decisões de um Tribunal, tipos de contratos e comportamentos dos contratantes sobre determinado tema). Após colher o material de análise, estes serão armazenados no sistema, organizados, calculados e expostos da forma mais clara possível (em gráficos, tabelas ou medidas), facilitando o trabalho do estatístico inferencial que irá extrair as características da população referente às variáveis em estudo. Através da análise inferencial, é possível obter, por exemplo, parâmetros de tomada de decisão do Poder Judiciário e compará-los com outros indicadores sociais existentes, verificando os 
seus efeitos perante a sociedade como um todo, podendo inclusive correlacionar estes parâmetros com as decisões de diversos Tribunais.

A Jurimetria inicialmente enfrenta as demandas jurídicas (judiciais e extrajudiciais) a partir de uma análise geral. Após a coleta de dados e organização dos mesmos, no estudo científico, é instintivo o levantamento de características ou variáveis em comum. Ao verificar situações com variáveis comuns, a princípio, os procedimentos e tomadas de decisões serão semelhantes. Após as constatações obtidas com a análise geral, será verificada a necessidade de análise da singularidade e particularidade de cada caso. Desta forma, a Jurimetria parte dos casos concretos para chegar a conclusões genéricas, e posteriormente as situações singulares são estudadas, considerando que estas geralmente representam uma parcela pequena da demanda. O estudo estatístico do Direito faz com que os conflitos jurídicos sejam apresentados em conjunto e não de forma isolada como ocorre atualmente.

A coleta de dados proporciona também uma perspectiva jurídica realizada de baixo para cima, ou seja, inverte-se o movimento de compreensão, que relaciona o caso concreto com os normativos (PINTO; MENEZES, 2015?). Consequentemente, os conflitos são compreendidos no contexto que foram produzidos e os momentos pré e pós-processuais passam a ser contínuos e dinâmicos. Quanto maior o banco de informações armazenadas, mais precisas são as conclusões.

Atualmente, os Estados Unidos contam com uma profusão de bancos de dados completos e altamente organizados, impressos e eletrônicos, públicos e privados, à disposição de todos, com destaque para o Westlaw e o Lexis Nexis. O sistema funciona da seguinte maneira: as Cortes estaduais e federais disponibilizam a integridade dos seus acórdãos, em suas respectivas páginas eletrônicas, minutos depois de serem proferidos, esses bancos de dados desenvolvem ementas e indexações padronizadas, colocando à disposição do público ferramentas de busca intuitivas e de fácil utilização (VEÇOSO et al, 2014, p.110).

No Brasil, vale a pena mencionar o crescimento do site de buscas de conteúdos jurídicos chamado JusBrasil ${ }^{5}$. O sistema trabalha com uma busca unificada de notícias, diários oficiais, legislações, jurisprudência, artigos e perfis em um único campo de busca. Atualmente, ao consultar os acórdãos, é possível verificar o andamento dos respectivos processos através de uma integração com os programas dos Tribunais que tramitam.

Ao convergir Direito e Estatística, a Jurimetria objetiva mensurar os fatos sociais que originaram os conflitos, permitindo a antecipação de hipóteses, pois se há alta probabilidade de

\footnotetext{
${ }^{5}$ Acesso em 20 abr. 2016: http://www.jusbrasil.com.br/home?ref=logo

PIDCC, Aracaju/Se, Ano VIII, Volume 13 no 01, p.110 a 131 Fev/2019 | www.pidcc.com.br
} 
determinados fatos terem como consequências o conflito, a tendência é que situações semelhantes encontrem os mesmos problemas, gerando novos atritos. O estudo dos casos potencialmente conflituosos permite uma projeção de determinadas condutas na elaboração das leis, no estabelecimento de políticas públicas, nas estratégias de administração do acervo em uma Vara Judicial, na racionalização para elaboração de decisões eficazes, e no resguardo do cliente pelo advogado quando pode prever atritos de forma mais precisa (PINTO; MENEZES, 2015?).

O estudo do Direito por meio da Jurimetria deixa de ser estritamente qualitativo, ou seja, baseado em classificações e atributos, objetivando uma congruência lógico-argumentativa, e passa a utilizar-se também da pesquisa quantitativa, como instrumento de teste e validação das suas teorias. Destarte, os modelos jurídicos de solução dos conflitos não serão mais estabelecidos de forma arbitrária e distante da realidade, considerando que a escolha de determinada demanda será visualizada concretamente e em seu conjunto, diferentemente da visão de unidade isolada que persiste atualmente.

\section{A POSSIBILIDADE DE PREVER COMPORTAMENTOS JURÍDICOS ATRAVÉS DE UMA ANÁLISE PROBABILÍSTICA}

\subsection{PREVISÃO DE COMPORTAMENTOS E SINGULARIDADE DAS RELAÇÕES} JURÍDICAS

O interesse da população em prever comportamentos foi abordado por Oliver Wendell Holmes (1897) ao afirmar que o estudo das Leis não poderia ser um mistério, tendo em vista que as pessoas as analisam com o objetivo de saber o que podem ou não desejar através da consciência sobre qual circunstância e em que medida correrão os riscos. Destarte, as pessoas contratam um advogado para auxilia-las e aconselha-las nesta ponderação.

A possibilidade de prever comportamentos jurídicos foi uma das teses propostas pela Jurimetria de Loevinger, em 1949, que sofreu críticas severas pelos autores, principalmente por aqueles que atuam no sistema que possui fortes características do Direito romano-germânico. A principal crítica baseia-se no pressuposto de mecanicidade das condutas humanas como única possibilidade de previsão dos comportamentos. Todavia, Loevinger nunca ignorou a singularidade das relações sociais e o processo de previsão de comportamentos jurídicos foi 
possível por meio da adoção de um viés estatístico. Este tópico objetiva demonstrar que sua utilização não encara os comportamentos como mecânicos.

A polêmica tese de previsão de comportamentos jurídicos foi explicada com profundidade em seu artigo Jurimetrics: Science and prediction in the field of Law (LOEVINGER, 1961). A tese desenvolveu a proposta da previsão de comportamentos no campo do Direito adaptando-se às críticas sofridas, principalmente, pelas limitações da sua teoria à época que fora desenvolvida. Em diversas passagens do seu artigo é possível verificar a aplicação da ideia de sistema e controle como fatores que interferem na tendência dos comportamentos em consonância com as teorias propostas pelo matemático e "pai" da cibernética Norbert Wiener (1954).

Para entender a possiblidade da criação de uma teoria que prevê comportamentos jurídicos com margem de êxito, sem mecanizar as condutas humanas, será realizada uma abordagem histórica sobre os principais conceitos científicos e sua influência no Direito, seguida da contribuição da Estatística e da Teleinformática como agentes viabilizadores da sua aplicação.

A disciplina científica, ao ser criada, não tinha qualquer intuito isolacionista. De acordo com Lee Loevinger (1961, p.187-189), a ciência é tão antiga quanto à própria consciência humana e seu objetivo primordial era investigar fenômenos através da observação, mensuração e experimentação. Desta forma, os métodos científicos fundamentais estavam intrínsecos em qualquer atividade e não era a certeza da premissa levantada que o aproximava à ciência, senão a sua aceitação pela sociedade que a utilizava .

Porém, a partir dos séculos de XVII e XVIII, com Copérnico e Galileu, a disciplina científica criou uma imagem de si baseada em estudos rigorosos e disciplinados que se iniciavam a partir do momento em que o cientista isolava-se em seu laboratório. Os critérios foram definidos no século XIX com a promessa de que, através da imparcialidade e universalidade, todos os problemas poderiam ser resolvidos, sejam eles sociais, legais e ambientais (LOEVINGER, 1961, 187-189).

O século XX foi marcado por avanços científicos, simbolizados principalmente com a criação da máquina eletrônica. O surgimento desta tecnologia propagou uma expectativa imediata de previsão e solução das questões jurídicas como um passe de mágica, devido à simples transformação da linguagem comum para a matemática.

É importante esclarecer que a ciência ofereceu ao Direito os instrumentos mecânicos e intelectuais. Porém, os mecanismos de comunicação por si só são mudos até que haja a 
interferência humana. ${ }^{6}$ A lógica matemática, aplicada na maioria das máquinas eletrônicas, e que ainda é utilizada atualmente pelas pessoas é formal e não tem nada de empírico, ela apenas analisa os comandos, relacionando-os e combinando-os, mas não critica a aplicação real destes comandos. É a lógica aristotélica da não contradição. A despeito disto, a utilização da Estatística tem o condão de oferecer instrumentos práticos nas ciências comportamentais.

Na prática, o Direito acabou afastando-se dos novos métodos científicos sustentados pelo positivismo, ao considerar que os valores presentes na sociedade deveriam fundamentar as decisões jurídicas, situação que impossibilitava a existência de uma verdade absoluta. Desta forma, a política de determinar os fatos por quantificação não é utilizada de forma constante, tendo em vista o obstáculo criado pela ideia de valor social de cada caso levado ao Judiciário para julgamento, que não poderia ser reduzido a números experimentais.

No intuito de contestar a verdade clara e manifesta defendida pelos cientistas, Foucault (1982, p.181) sustenta que os significados de determinados princípios variam de acordo com a época analisada, recortando na experiência social um campo de saber possível. Ao definir o modo de ser dos objetos que nele aparecem, "arma-se o olhar cotidiano de poderes teóricos e define as condições em que se pode enunciar sobre as coisas em discurso reconhecido como verdadeiro".

A precisão estatística está na amostragem, na seleção inicial da população a ser pesquisada e não tem a pretensão de trazer conclusões absolutas, principalmente ao Direito. Os resultados do trabalho estatístico limitam-se à amostra, a qual pode ser utilizada para um estudo comparativo com outras pesquisas. Destarte, a Estatística não desconsidera os valores dos grupos, ao contrário, os estudos de diversas amostragens, inclusive abarcando diferentes períodos, são os instrumentos de avaliação e correspondência das teses dos próprios cientistas sociais.

\subsection{PROBABILIDADE PRAGMÁTICA E A QUANTIFICAÇÃO DAS EVIDÊNCIAS}

O desenvolvimento da inteligência artificial vem se pautando cada vez mais nos comportamentos humanos. Além de realizar inferências dedutivas, os homens utilizam-se de raciocínios extraídos da experiência, da analogia, da indução e também da estatística. No

\footnotetext{
${ }^{6}$ Atualmente, devido ao estudo da inteligência artificial, que será abordado no tópico seguinte, já existem máquinas avançadas, denominadas robôs, que são preparadas para criar sua própria programação. Porém, a afirmação trazida neste capítulo possui o viés didático de abordar o impacto que as máquinas trouxeram ao público na época que entraram no mercado.
} 
momento que a Lógica Paraconsistente, desenvolvida pelo matemático brasileiro Newton da Costa, em 1963, une-se à Teoria das Probabilidades, um eficiente método de tratamento de incertezas é criado e denominado pelo próprio autor de "Probabilidade Pragmática" (DA SILVA, 2008).

A lógica indutiva paraconsistente admite o processamento de conclusões em enunciados contraditórios e tem sido utilizada em tratamento de crenças, níveis de incertezas e inconsistências. Em consonância ao pensamento de Loevinger, as sentenças proposicionais iniciam-se como quase-verdade ou verdade pragmática e são acompanhadas de graus de evidência favoráveis ou desfavoráveis, responsáveis pela ratificação da verdade ou falsidade e inconsistência.

Precisões científicas são capazes de mensurar ou quantificar determinações apenas de forma aproximada. Claro que seu grau de certeza, entendida como credibilidade dos receptores, já possibilita diversas aplicações práticas, entretanto, há uma porcentagem de escape, pois, ao analisar um fato ou ato jurídico, diversas situações legais estarão em evidência. $\mathrm{O}$ destaque às evidencias é de certa forma pessoal, e não há como garantir que os advogados, as partes e os juízes irão analisá-lo com o mesmo nível de relevância em cada uma de suas peculiaridades. Resta então ao advogado utilizar as suas habilidades para destacar os fatos em cotejo com a argumentação no intuito de chamar a atenção do julgador aos interesses do seu cliente (LOEVINGER, 1961, p.193-194).

A noção de probabilidade é fundamental para entender a utilidade da ciência contemporânea. A probabilidade é a frequência com que determinado evento ocorre se comparado com outros eventos da mesma categoria. Um exemplo é a probabilidade de uma moeda lançada apresentar as imagens da "cara" ou "coroa" obtida pela análise de lançamentos pretéritos.

A essência da utilização da frequência é a mesma tanto nos comportamentos humanos quanto no lançamento de uma moeda, tendo em vista que a análise é empírica e baseia-se quantitativamente em fatos passados. A diferença é que as variáveis a serem calculadas no último caso são muito mais simples que no primeiro, porque as relações humanas possuem diversos pontos a serem analisados.

Observa-se, portanto, que as conclusões científicas não passam de probabilidades. $\mathrm{Na}$ realidade, a ciência não busca conclusões ou julgamentos, e também não pode acertar o futuro a não ser em termos de previsões, pautada em graus de certezas. Em princípio, a probabilidade não é nem totalmente certa ou errada e também não desconsidera qualquer resultado que venha a ser observado no futuro. Entretanto, na prática, as afirmações probabilísticas podem ser PIDCC, Aracaju/Se, Ano VIII, Volume 13 no 01, p.110 a 131 Fev/2019 | www.pidcc.com.br 
metodologicamente utilizadas como premissas verdadeiras ou falsas de acordo com a sua porcentagem de certeza. Este é o procedimento da previsão, conceituada como a quantificação da probabilidade, e aplicada com base em eventos passados (LOEVINGER, 1961, p.195-196).

O conceito de probabilidade não é de difícil compreensão. Todavia, o maior problema que a teoria vem enfrentando está na sua aplicação quando é confrontada com os casos considerados singulares. Um exemplo recente deste impacto foi verificado em uma pesquisa realizada no ano de 2013, pela Fundação Getúlio Vargas do Rio de Janeiro, que fez uma previsão considerando as chances do Supremo Tribunal Federal reverter uma decisão do Tribunal Regional Federal da $4^{\mathrm{a}}$ Região, desfavorável aos réus da operação Lava Jato, concluindo que esta seria de apenas $1 \%$. A pesquisa analisa a taxa de derrota do Ministério Público Federal ao figurar como recorrido no Supremo. ${ }^{7} \mathrm{O}$ ministro do STF, Marco Aurélio, criticou a previsão alegando "cada cabeça, uma sentença, não julgamos um processo pensando pela capa, não levamos em conta quem é parte. Nunca estivemos preocupados se a balança pende mais para a defesa ou se deixa mais pesado o prato da acusação". A crítica foi seguida pelo doutrinador Lênio Streck, ao afirmar que "pesquisas assim são como profecias sobre o passado. Seu perigo é influenciarem o futuro. Só que sem nexo com a realidade" (MELLO; STRECK apud VASCONSELOS, 2016).

As críticas sofridas pela pesquisa da respeitável Fundação, que está entre as dez melhores think tanks ${ }^{8}$ do mundo, de acordo com a Global Go To Think Tanks Rankings 2015 (THINK TANKS AND CIVIL SOCIETIES PROGRAM, 2015), ignoram o fato de que, não é porque um caso é considerado único, que uma situação semelhante não pode ocorrer novamente. Singularidade é uma maneira simples de nivelar diferenças e não apenas uma categoria distinta de casos a serem defrontados. Qualquer caso é único em algum aspecto, mas possui variáveis em comum com outros da amostra. Pensar diferente retiraria o sentido em discutir qualquer fato, considerando que uma situação idêntica nunca se repetirá.

No momento que determinados princípios passam a ser constantes em um grupo em análise, o órgão julgador deve realizar sua função baseando-se na coerência, ou seja, as decisões

\footnotetext{
${ }^{7}$ Conforme a pesquisa da fundação, que analisou milhares de processos, no início dos anos 2000, a taxa de derrota de todas as Procuradorias Regionais Federais sofreu uma redução significativa, mantendo-se, em geral, em 30\%. Porém, a partir de 2007, essa taxa foi reduzida para faixa dos $10 \%$ e quase sempre abaixo da média do Tribunal. Em 2013, a média do Supremo era de 5,7\%, enquanto que a taxa de derrota das Procuradorias da $2^{\mathrm{a}}$ e $5^{\mathrm{a}}$ Regiões eram, respectivamente, $2 \%$ e $3 \%$, a da $4^{\text {a }}$ Região foi calculada em apenas $1 \%$.

${ }^{8}$ De acordo com o Instituto Millenium "o think tank faz referência a uma instituição dedicada a produzir e difundir conhecimentos e estratégias sobre assuntos vitais - sejam eles políticos, econômicos ou científicos. Assuntos sobre os quais, nas suas instâncias habituais de elaboração (estados, associações de classe, empresas ou universidades), os cidadãos não encontram facilmente insumos para pensar a realidade de forma inovadora." Mar. 2017, acesso em http://www.institutomillenium.org.br/artigos/o-que-significa-um-think-tank-no-brasil-de-hoje/
} 
no Direito necessitam de uma certa precisão, não obstante levem em consideração os valores sociais. Pode-se concluir que é função da ciência determinar, na medida do possível, a importância, ainda que ponderável, dos diferentes fins sociais através da estimativa e da proporção entre eles. A estatística e todas as máquinas de ponta auxiliam o cientista na busca destes cálculos. É difícil pensar na constituição de uma comunidade na qual a ciência seja universal e suprema, porém, é possível encontrar um ideal comum, considerando que, sem os ideais, os próprios valores perderiam o sentido (LOEVINGER, 1961, p.190-192).

As previsões legais são atividades que tanto os advogados quanto os cidadãos se preocupam. A análise de comportamentos jurídicos transcende os julgados do Judiciário para englobar atitudes preventivas no intuito de evitar conflitos, criar estratégias de negociação para solução extrajudicial ou verificar a possibilidade de êxito no ingresso de uma ação judicial.

Torna-se necessário, então, otimizar e automatizar os procedimentos dos setores jurídicos que através de uma monitoração contínua possam gerar indicadores de desempenho. O software tornou-se uma ferramenta imprescindível para identificação dos principais focos de riscos jurídicos do negócio bem como da sua quantificação, pautada na estatística, e essencial para previsão de comportamentos.

\section{A ADVOCACIA PREVENTIVA}

Os advogados têm a possibilidade de prever consequências jurídicas frente à determinado fenômeno, através da análise dos dados dispostos e interpretados pelos jurimétricos. A previsão de comportamentos dá origem a nova abordagem da Advocacia, denominada de preventiva.

A importância da teoria preventiva está intimamente ligada ao risco jurídico, pois quando uma consequência nociva deixa de ser algo em potencial para ser efetiva, saindo do âmbito das possibilidades ou probabilidades, para adentrar no mundo fenomenológico, como fato concreto, sua eliminação ou amortização será mais trabalhosa, trazendo consequências danosas às partes lesadas (FERREIRA, 2014). As ferramentas que visam prever riscos no intuito de evita-lo ou mitiga-lo não constituem uma perspectiva distante, pois empresas e acadêmicos já as colocaram em ação.

Em 2004, através de um projeto interdisciplinar, cientistas políticos desenvolveram um sistema que identificou o perfil de tomada de decisões da Suprema Corte Americana, com base na coleta de dados referentes aos seus julgamentos anteriores. Utilizando-se de um modelo estatístico para previsão das futuras decisões, o software foi capaz de prever corretamente $75 \%$ 
dos seus julgamentos enquanto que um conjunto de juristas experts no assunto da Corte alcançou o percentual de acerto de 59,1\% (RUGER et al, 2004).

No Brasil, Marcelo Nunes e Fabio Ulhoa Coelho (2010) trabalharam em seu artigo com o exemplo de uma pesquisa publicada pelo Instituto de Direito Societário Aplicado (IDSA) sobre intervenção judicial na administração, baseada em levantamento de acórdãos do Tribunal de Justiça de São Paulo. Foram analisadas amostras de decisões expondo os posicionamentos dos desembargadores sobre o tema, bem como a fundamentação utilizada. A pesquisa revelou aspectos relevantes que indicam a posição deste Tribunal nos casos de intervenção estatal na gestão de empresas e provavelmente o seu resultado refletirá na estratégia de atuação dos advogados que litigam na área.

A Jurimetria é uma ferramenta de grande relevância para advogados, tanto na sua utilização voltada à previsão de comportamentos jurídicos, como para evidenciar a necessidade dos pedidos formulados em um processo judicial. As medidas de evidência oferecem suporte à argumentação, que passa a ser baseada em dados demonstrados e interpretados estatisticamente. Ressalte-se ainda que as informações devem ser calculadas a partir de dados de fácil acesso, preferencialmente os públicos.

No artigo Jurimetria aplicada ao Direito, Zabala e Silveira (2014, p.94-96) trazem duas situações ilustrativas para utilização da Jurimetria como meio de evidência e técnica hábil a fundamentar o pedido de antecipação dos efeitos da tutela, preenchendo o requisito "fundado receio de dano irreparável ou de difícil reparação". O primeiro exemplo refere-se a uma ação envolvendo pedido de cirurgia, sendo possível juntar com a petição inicial uma planilha de análise estatística que indique a chance de haver graves sequelas e até a morte do paciente, caso não seja realizada com urgência. Metodologia semelhante deveria ser aplicada quando uma empresa requer indenização por negativação indevida nos órgãos restritivos, pois pessoas jurídicas costumam consultar estes bancos de dados com o fim de verificar a idoneidade dos negociantes. Os órgãos restritivos passam estas informações, o que permite uma estimativa precisa da quantidade de vendas não realizadas após a negativação, aumentando as chances de persuasão do juiz.

A verificação das cláusulas contratuais majoritariamente descumpridas, as garantias mais efetivas e as situações societárias com maior potencial de causar desavença entre os sócios oferecem subsídios relevantes para construção da estratégia na condução do caso. Além disto, na análise de uma ação, é possível avaliar e quantificar as chances de êxito do cliente ganhar a causa, através da coleta de dados de variáveis comuns, como a jurisprudência consolidada 
para demandas de massa. Pode-se ainda verificar a viabilidade econômica de se ingressar com a ação, através dos dados financeiros. Por fim, os honorários também podem ser cobrados de forma mais precisa, utilizando-se da probabilidade de "chance de sucesso", nos casos que estes são condicionados ao êxito.

Para a advocacia, a Jurimetria tem diversas aplicações, sendo que todas elas trazem como consequência uma proteção aos clientes, lastreadas na pesquisa de previsão de resultados, sejam eles proveniente das relações entre contratantes, das decisões no processo judicial ou até mesmo servindo como embasamento técnico para antecipação de resultados futuros em casos de pedidos judiciais de urgência. A utilização da estatística pelos advogados assegura a confiança na relação com o cliente ao fundamentar os argumentos jurídicos em subsídios sólidos.

\section{CONCLUSÕES}

O comportamento humano é pautado por incertezas e pelo conhecimento limitado do mundo. A tentativa de compreender estas relações incitou teorias de cientistas de diversas áreas do conhecimento. Entretanto, a Ciência do Direito não foi capaz de cooperar significativamente com teses de previsão de comportamentos e mitigação dos riscos.

A primeira justificativa para a ausência de contribuição do Direito em relação à possibilidade de prever comportamentos está na própria discussão sobre o seu caráter científico. A necessidade de testar teses jurídicas ainda não ganhou a importância necessária pelos seus aplicadores e reprodutores, os quais costumam manter-se afastados da realidade social. Este tipo de conduta dá margem a argumentos e opiniões, sustentados exclusivamente pela autoridade que os propagou.

A interdisciplinaridade do Direito com as ciências quantitativas como Estatística e Matemática foi inicialmente apresentada como solução para aproximá-lo da realidade e propiciar, assim, a sua legitimação social. Neste contexto, surge a Jurimetria objetivando extrair conclusões a partir da coleta de dados de uma amostra, o armazenamento, a organização, cálculo e interpretação dos resultados. A Jurimetria afirma que a partir da análise de uma intensa quantidade de informações organizadas, pode-se prever comportamentos no mundo jurídico.

Para entender a possiblidade da criação de uma teoria que prevê comportamentos jurídicos com margem de êxito, sem mecanizar as condutas humanas, foi feito no artigo uma pequena regressão ao conceito de ciência como incapaz de proporcionar uma certeza da premissa levantada, considerando exclusivamente a aceitação das suas teorias pela sociedade 
que a utiliza. Porém, a deturpação do seu conceito durante séculos por cientistas que prometeram trazer soluções através da imparcialidade e universalidade empregada em seus métodos e conclusões, acabou afastando o Direito da ciência.

O mundo jurídico atual refuta a existência de uma verdade absoluta, em respeito aos valores presentes na sociedade que devem fundamentar as decisões jurídicas. Apesar de utilizar métodos matemáticos, a Estatística não desconsidera os valores dos grupos e consegue aproximar as ciências da realidade devido à limitação da amostragem, ou seja, a seleção inicial da população a ser pesquisada. Assim, o estudo jurimétrico não tem a pretensão de trazer conclusões absolutas, mas é capaz de constatar, por exemplo, a existência de comportamentos jurídicos semelhante nas relações entre pessoas que sequer habitam no mesmo país ou região.

Em 1963, o matemático brasileiro Newton da Costa une a Lógica Paraconsistente à Teoria das Probabilidades, desenvolvendo a tese da Probabilidade Pragmática, a qual admite o processamento de conclusões em enunciados contraditórios. Considerando que a probabilidade pragmática lida com a noção de níveis de certeza, a sociedade adota como verdade as semelhanças postas em evidência, sem olvidar que as proposições são apenas tendências e passam a ser refutadas no momento que o seu grau de evidência desfavorável aumenta.

O estudo das previsões comportamentais é um marco do século. A Teoria da Probabilidade Pragmática vem permitindo o desenvolvimento da inteligência artificial pautada cada vez mais nos comportamentos humanos. Considerando que a capacidade de um software armazenar e combinar informações é exponencialmente maior que a mente do homem, os tomadores de decisão devem focar as energias nas habilidades que complementam o trabalho dos sistemas, construindo estratégias e meios criativos para condução de casos jurídicos.

Os advogados já incorporaram a tendência e denominaram de advocacia preventiva as estratégias que objetivam evitar situações potencialmente conflituosas, resguardando antecipadamente os interesses dos seus clientes. A advocacia preventiva baseada no estudo jurimétrico permite uma análise dinâmica e coerente dos fenômenos, com consequente vantagem na técnica de modelar e prever comportamentos.

\section{REFERÊNCIAS}

BARROS, Carla Eugenia Caldas. Manual de Direito da Propriedade Intelectual, Evocati: Aracaju, 2007.

BARROS, Carla Eugenia Caldas. Aperfeiçoamento e Dependência em Patentes, Lumen Juris: Rio de Janeiro, 2004 
BERNOULLI, De usu artis conjectandi in jure, 1709 apud ZABALA, F. J.; SILVEIRA, F. F. Jurimetria: Estatística aplicada ao Direito. Direito e Liberdade, ed. ESMARN 16 v., n. 1, 29 abr. 2014, p. 87-103. Disponível em: $<$ http://www.esmarn.tjrn.jus.br/revistas/index.php/revista_direito_e_liberdade/article/downl oad/732/596>. Acesso em: 07/12/2015.

BISQUERRA, Rafael; SARRIERA, Jorge C., MATÍNEZ, Francesc. Introdução a Estatística: enfoque informático com o pacote estatístico SPSS. Porto Alegre, Artes Médicas, 2007.

CASTRO, Ricardo Medeiros de. Novas conformações metodológicas em relação à Jurimetria: discussão teórica e implicações práticas para a regulação de preços no Brasil. Revista de Direito Setorial e Regulatório, Brasília, v. 1, n. 2, out. 2015. Disponível em http://www.ndsr.org/SEER/index.php?journal=rdsr\&page=article\&op=view\&path $\% 5 \mathrm{~B} \% 5 \mathrm{D}=$ 121. Acesso em: 25/05/2016.

DA SILVA FILHO, João Inácio. Lógica Paraconsistente e Probabilidade Pragmática no Tratamento de Incertezas. Revista Seleção Documental do GLPA. Artigos Técnicos e Científicos de Inteligência Artificial e Novas Tecnologias. Ed. Paralogike, Santos, n. 9, 2008. Disponível em http://webcache.googleusercontent.com/search?q=cache:o6y690ZHRj4J:www.paralogike.co m.br/Logica $\% 2520$ Paraconsistente $\% 2520 \mathrm{e} \% 2520$ Probabilidade $\% 2520$ Pragmatica $\% 2520 \mathrm{no} \%$ 2520Tratamento $\% 2520 \mathrm{de} \% 2520$ Incertezas.pdf $+\& \mathrm{~cd}=1 \& \mathrm{hl}=$ pt-BR\&ct $=\mathrm{clnk} \& \mathrm{gl}=$ br. $\quad$ Acesso em: 13/03/2017.

FERREIRA, Marcelo José Ferraz. Jurimetria? Sim. Jurimetria. Revista Digital Exame, 2015. Disponível em http://jurimetria.oabpr.org.br/jurimetria-sim-jurimetria.html. Acesso em: 06/11/2015.

FOUCAULT, M. Microfisica do poder. Tradução de Roberto MACHADO. Rio de Janeiro: Graal, 1982.

HEISE, Michael. The importance of being empirical. Pepperdine Law Review, Ithaca, NY, v. 26, n. 807, 1999, p. 807-834. Disponível em: http://scholarship.law.cornell.edu/cgi/viewcontent.cgi?article $=1532 \&$ context $=$ facpub Acesso em: 22/01/2016.

HOLMES, Oliver Wendell. The path of the law. 10 Harvard Law Review, v. 457. 1897. Disponível em: http://www.constitution.org/lrev/owh/path_law.htm. Acesso em 02/10/2015.

JURIMETRICS. American Bar Association. Disponível em http://www.americanbar.org/publications/jurimetrics/2015/summer.html. Acesso em: $15 / 12 / 2015$.

JusBrasil. Disponível em http://www.jusbrasil.com.br/home?ref=logo. Acesso em: 20/04/2016.

KELSEN, Hans. Teoria Pura do Direito. Traduzido por João Baptista Machado. 6.ed. São Paulo: Martins Fontes, 1998.

LOEVINGER, Lee. Jurimetrics: the methodology of legal inquiry. Duke University School of Law. Law and Contemporary Problems, Durham, NC, 28 v, n. 1, p. 5-35, winter 1963. 
Lee. Jurimetrics: science and prediction in the field of Law. Proceedings of the special committee on electronic data retrieval. MULL: Modern Uses of Logic in Law, Vol. 3, n. 3, St. Louis, Missouri, p. 187-205, set. 1962.

NUNES, Marcelo; COELHO, Fabio Ulhoa; Pesquisas a Serviço da Advocacia. Jornal Valor Econômico, 28 ago. 2010, Disponível em: http://www.valor.com.br/arquivo/842723/pesquisasservico-da-advocacia. Acesso em: 01/02/2016.

PINTO, Felipe Chiarello de Souza; MENEZES, Daniel Francisco Nagao. Jurimetria: $\begin{array}{llllll}\text { construindo } & a & \text { teoria, } & \text { p. } & \text { 27-42. } & \text { Disponível }\end{array}$ http://www.publicadireito.com.br/artigos/?cod=90797bef9ef6175e. Acesso em: 16/01/2016.

RUGER, Theodore W. et al., The Supreme Court Forecasting Project: legal and political science approaches to predicting Supreme Court decision making. Berkeley Law Scholarship Repository, Berkeley, v. 104, 2004, p. 1150-1209. Disponível em http://scholarship.law.berkeley.edu/cgi/viewcontent.cgi?article=1018\&context=facpubs.

Acesso em: 22/05/2016.

SERRA, Márcia Milena Pivatto. Como utilizar elementos da Estatística descritiva na Jurimetria. Revista Eletrônica do Curso de Direito das Faculdades OPET, Curitiba, v. IV, no 10, jun/dez 2013, p. 156-169. Disponível em: <http://www.anima-opet.com.br/pdf/anima10/8marcia-milena-jurimetria-anima10.pdf $>$. Acesso em: 16/12/2015.

SILVA, André Queiroz Lacerda e. Análise de argumentos jurídicos com lógica deôntica paraconsistente, 2012, 97 f. Monografia em Lógica Jurídica, Centro Universitário de Brasília, Brasília. Disponível em: $<$ http://repositorio.uniceub.br/bitstream/235/4085/1/Andr\%C3\%A9\%20Queiroz\%20Lacerda $\% 20 \mathrm{e} \% 20$ Silva\%20RA\%2020355212.pdf>. Acesso em: 17/12/2015.

Think Tanks and Civil Societies Program. University of Pennsylvania. Disponível em http://gotothinktank.com/2015-global-go-to-think-tank-index-report/. Acesso em: 12/03/2017.

VASCONCELOS, Marcos. Estudo gera polêmica ao usar estatística para prever resultado de processo. Revista Consultor Jurídico, 2016. Disponível em http://www.conjur.com.br/2016fev-03/estudo-gera-polemica-usar-estatistica-prever-fim-acao. Acesso em: 07/02/2016.

VEÇOSO, Fabia Fernandes Carvalho et al. A pesquisa em direito e as bases eletrônicas de julgados dos Tribunais: matrizes de análise e aplicação no Supremo Tribunal Federal e no Superior Tribunal de Justiça. Revista de Estudos Empíricos em Direito, Veçoso, v. 1, n. 1, 2014. Disponível em http://www.reedpesquisa.org/ojs-2.4.3/index.php/reed/article/view/10. Acesso em 29/01/2016.

WIENER, Norbert. Cibernética e sociedade: o uso humano em seres humanos. Tradução de José Paulo Paes. 2. ed., São Paulo, CULTRIX, 1954.

ZABALA, F. J.; SILVEIRA, F. F. Jurimetria: Estatística aplicada ao Direito. Revista Direito e Liberdade, ed. ESMARN, Natal, v. 16, n. 1, p. 87-103, jan./abr. 2014. Disponível em: $<$ http://www.esmarn.tjrn.jus.br/revistas/index.php/revista_direito_e_liberdade/article/downl oad/732/596>. Acesso em: 09/01/2016. 
ZANATTA, Rafael Augusto Ferreira. Desmistificando a Law \& Economics: A Receptividade da Disciplina Direito e Economia no Brasil. Revista dos Estudantes de Direito da Universidade de Brasília, Distrito Federal, v. 10, p. 25-53, 2012. Disponível em http://periodicos.unb.br/index.php/redunb/article/view/7095. Acesso em: 15/01/2016. 